\title{
A CONTRARREFORMA DO ENSINO MÉDIO NO CONTEXTO DA NOVA ORDEM E PROGRESSO*
}

\author{
Eliza Bartolozzi Ferreira ${ }^{1}$
}

\begin{abstract}
RESUMO: O texto objetiva discutir a contrarreforma do Ensino Médio empreendida pelo atual governo (Lei $\mathrm{n}^{\circ}$ 13.415, 16 de fevereiro de 2017). Na perspectiva de viver o presente como já possuído de um sentido histórico, a compreensão do artigo sustenta que essa lei guarda o mesmo espírito das políticas educacionais ocorridas no Ensino Médio brasileiro na ditadura varguista, na ditadura militar e nos anos 1990. Além de apresentar um conteúdo que tende a aprofundar as desigualdades escolares, a contrarreforma do Ensino Médio foi forjada por um grupo restrito de atores ligados fortemente aos interesses privatistas. Ao contrário, portanto, das experiências vividas durante o governo democrático-popular (2003-2015) de inclusão social e de participação dos diversos segmentos da sociedade.
\end{abstract}

Palavras-chave: Ensino Médio. Contrarreforma. Desigualdades escolares.

\section{THE COUNTER-REFORM OF HIGH SCHOOL IN THE CONTEXT OF THE NEW ORDER AND PROGRESS}

\begin{abstract}
The text aims to discuss the counter-reform of high school undertaken by the current government (Law 13,415, February 16, 2017). In the perspective of living the present as already possessed of a historical sense, the understanding of the article maintains that this law bears the same spirit of the educational policies that occurred in Brazilian high school in the Vargas dictatorship, in the military dictatorship and in the 1990s. In addition of presenting the content that tends to deepen school inequalities, the counter-reform of high school was forged by a narrow group of actors strongly linked to privatizing interests. Contrary, therefore, to the experiences lived during the democratic-popular government (2003-2015) of social inclusion and participation of the various segments of society.
\end{abstract}

Keywords: High school. Counter-reform. School inequalities.

\footnotetext{
*A produção deste texto está inserida nos estudos desenvolvidos na pesquisa "Programa ensino médio inovador: condiçóes de trabalho e formação docente" (CNPq - no do processo: 482975/2013-0). ${ }^{1}$ Universidade Federal do Espírito Santo - Vitória (ES), Brasil. E-mail: eliza.bartolozzi@gmail.com DOI: 10.1590/ES0101-73302017176594
} 


\title{
LA CONTRE-RÉFORME DE L'ENSEIGNEMENT SECONDAIRE DANS LE CADRE DU NOUVEL ORDRE ET PROGRÈS
}

\begin{abstract}
RÉSUMÉ: Cet article vise à discuter la contre-réforme de l'enseignement secondaire entrepris par le gouvernement actuel (loi $n{ }^{\circ} 13415$, le 16 Février 2017). Dans la perspective de vivre le présent comme s'il possédait déjà un sens historique, la compréhension de l'article précise que la loi conserve le même esprit de la politique de l'éducation qui a eu lieu dans les lycées brésiliens à la dictature Vargas, à la dictature militaire et dans les années 1990, Au-delà de présenter un contenu qui tend à aggraver les inégalités scolaires, la contre-réforme de l'enseignement secondaire a été forgée par un petit groupe d'acteurs étroitement liés aux intérêts privatistes. Au contraire, par conséquent, des expériences vécues pendant le gouvernement populaire démocratique (2003-2015), d'inclusion sociale et de participation des différents segments de la société.
\end{abstract}

Mots-clés: École secondaire. Contre-Réforme. Inégalités scolaires.

\section{Introdução}

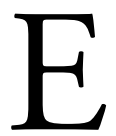

ste texto tem por objetivo contribuir para a discussão sobre a contrarreforma do Ensino Médio empreendida pelo atual governo, cujo slogan adotado é "ordem e progresso". Essa contrarreforma, inicialmente conhecida por meio da edição de uma medida provisória de $\mathrm{n}^{\circ} \mathbf{7 4 6}$, de julho de 2016, foi agora transformada em lei - Lei no 13.415, 16 de fevereiro de 2017. A análise desenvolvida defende que se trata de uma contrarreforma, tal como defendido por Behring (2003), quando estudou o profundo retrocesso das políticas sociais ocorrido na década de 1990. Naquela ocasiáo, a autora se recusou a vincular o conceito de reforma a processos regressivos, pois esse conceito faz parte do debate do movimento operário, como uma estratégia revolucionária. "O reformismo, ainda que se possa e deva criticá-lo, como o fez Rosa Luxemburgo, é um patrimônio da esquerda” (BEHRING, 2003, p. 211).

$\mathrm{Na}$ perspectiva de "viver o presente como já possuído de um sentido histórico" (NORA, 1988, p. 180), a compreensão do artigo sustenta que essa lei guarda o mesmo espírito das políticas educacionais ocorridas no ensino médio brasileiro na ditadura varguista, na ditadura militar e nos anos 1990. Além de apresentar um conteúdo que tende a aprofundar as desigualdades escolares, a contrarreforma do ensino médio foi forjada por um grupo restrito de atores ligados fortemente aos interesses privatistas e mercantis. Ao contrário, portanto, das experiências vividas durante o governo democrático-popular (2003-2015), caracterizado por práticas políticas de inclusão social, que mesmo difusas, contaram com a participação de um conjunto mais ampliado da comunidade educacional. 
Para início da discussão, o texto destaca as principais preocupações que emergem quando o ensino médio é objeto de análise entre os pesquisadores e outros segmentos da sociedade civil. Grosso modo, a seção primeira reflete sobre a necessidade de fazer reformas que vão ao encontro da universalização dessa etapa da educação básica, incorporando aqueles que estão fora das escolas e oferecendo condiçóes físicas, materiais e de trabalho, para que se possa pensar em escolas mais atrativas para a juventude, tendo em vista o conteúdo do discurso dos atores da contrarreforma.

A segunda seção deste texto procura recuperar os esforços políticos e normativos realizados desde 2003, início do governo de Luiz Inácio Lula da Silva. É importante fazer esse resgate, já que o governo atual argumenta que decidiu editar uma medida provisória porque até então nada foi feito no ensino médio. Os grandes meios de comunicação reforçam esse argumento e, ao contrário do que é dito, essa sessão mostra que os governos do PT fomentaram a abertura de debates e decisóes políticas e normativas que favoreceram o surgimento de novas experiências para professores e alunos do ensino médio, as quais precisavam de um tempo mais longo de implantação e de um exercício mais efetivo de colaboração entre os entes federativos.

A atual contrarreforma do ensino médio é analisada na terceira seção deste texto como parte integrante da "agenda globalmente estruturada da educação" (DALE, 2004). O objetivo é questionar os principais argumentos, aqueles declarados pelos seus defensores, que deram origem a essa contrarreforma.

\section{O ensino médio como problema}

O estudo de Krawczyk (2009) ressalta que, quando se trata de refletir sobre o sistema educacional brasileiro, é consensual a percepção de que o ensino médio é o nível de ensino que provoca os debates mais controversos, seja pelos persistentes problemas do acesso e da permanência, seja pela qualidade da educação oferecida ou, ainda, pela discussão sobre a sua identidade.

Para Enguita (2014), com referência às experiências europeias, o nível médio de ensino foi e ainda é a encruzilhada estrutural do sistema educativo, sendo o ponto no qual uns fatalmente terminam e outros verdadeiramente começam, no qual se jogam os destinos individuais que podem depender da educação, no qual se encontram ou se separam — segundo as políticas públicas e as práticas profissionais — os distintos grupos sociais.

Merle (2009), em estudo sobre a expansão dos diplomas ocorrida entre 1985 e 1995 na França, considera que a expansão do ensino secundário francês tem o caráter de uma "democratização segregativa". Pois o acesso ao "baccalauréat" ${ }^{1}$ dos jovens das classes populares foi essencialmente realizado graças à difusão do diploma tecnológico, sobretudo profissional. Assim, o autor analisa que o tipo de diploma obtido pelos jovens é um vetor de desigualdade social. 
Essas reflexóes sobre a escola secundária expressam que há um problema, ele é histórico e compartilhado por vários países. Se a questão é analisada em termos de acesso e da permanência no ensino médio, o Brasil apresenta um grande desafio, não obstante a ampliação ocorrida desde a década de 1990, a qual elevou o número de matrículas para uma taxa de 82,5\% entre os jovens de 15 a 17 anos. Há também uma população grande de jovens de 18 a 24 anos de idade que não cumpriu a educação básica. Outro grande desafio é transformar a etapa do ensino médio em uma referência de qualidade.

Mas o próprio conceito de qualidade precisa ser esclarecido, pois se trata de uma categoria histórica e socialmente construída. Portanto, está relacionada a uma concepção de mundo e de educação. Por muito tempo, no século XX, as políticas para o ensino médio perseguiram a ideia de ajustar seu projeto pedagógico aos preceitos da Teoria do Capital Humano (TCH). Com isso, a escola tornou-se improdutiva para servir à produção do capital (FRIGOTTO, 1988). O ensino médio ficou restrito a uma pequena elite e quando expandido, ainda de forma limitada, foi para atender estritamente às exigências da formação de mão de obra para o setor produtivo.

Em relação à igualdade de chances que supostamente poderia ser promovida pela escolarização secundária, promove-se outro mito problemático. Desde 1930, o ensino médio assumiu uma forma específica de dualidade que se distingue pela oferta de diversas modalidades e pela segmentação e diferenciação dos processos educativos que tratam as diferentes classes sociais de forma desigual. Em 1942, a Reforma Capanema criou os cursos médios de segundo ciclo, científico e clássico, para as classes mais privilegiadas. Com a edição das Leis Orgânicas, a formação profissional destinada aos trabalhadores passou também a contar com alternativas em nível médio de segundo ciclo: o agrotécnico, o comercial técnico, o industrial técnico e o normal, os quais não davam acesso ao ensino superior.

Com a edição da Lei de Diretrizes e Bases da Educação Nacional (Lei no 4.024/61), houve o reconhecimento da integração entre o ensino profissional e o ensino regular de segundo ciclo para fins de prosseguimento de estudos. Todavia, a dualidade estrutural permaneceu porque continuaram a existir dois ramos distintos de ensino.

Em 1971, por meio da Lei no 5.692, foi estabelecida a profissionalização compulsória no ensino de segundo grau e, com isso, todos passaram a ter a mesma trajetória escolar. Essas mudanças na organização do ensino médio foram realizadas sem consultas à sociedade, pois o tempo era de autoritarismo e cerceamento dos movimentos sociais. Cunha (1991) mostrou que a intencionalidade dessa lei foi inibir a "corrida" para o ensino superior. Em 1975, com o Parecer no 76, depois com a Lei no 7.044/82, foi restabelecida a modalidade de educação geral. As "escolhas" passaram a ser dos professores e alunos.

Com essa trajetória de reprodução da desigualdade social entre os jovens, a reflexão sobre a qualidade do ensino médio pressupóe expandir sua oferta 
de forma a atender às necessidades dos jovens para que se mantenham na escola em situação de igualdade. Além disso, é importante assumir a concepção construída no ambiente da Conferência Nacional de Educação (CONAE, 2014), que, coletivamente, compreende a "educação de qualidade" como aquela que contribui com a formaçáo dos estudantes nos aspectos humanos, sociais, culturais, filosóficos, científicos, históricos, antropológicos, afetivos, econômicos, ambientais e políticos, para o desempenho de seu papel de cidadáo no mundo, tornando-se, assim, uma qualidade referenciada no social. Nesse sentido, o ensino de qualidade está intimamente ligado à transformação da realidade na construção plena da cidadania e na garantia aos direitos humanos.

Com base em um projeto social inclusivo e em uma concepção de qualidade socialmente referenciada, uma reforma do ensino médio precisa enfraquecer a relação determinante entre a origem social dos jovens e seu percurso escolar. Exige, assim, o compartilhamento de estudos científicos capazes de construir um diagnóstico mais fiel da realidade, além de esforços políticos colaborativos entre os entes federativos.

Outro importante aspecto é compreender as juventudes e seus contextos de modo a favorecer suas potencialidades. Não se trata apenas de mudar o currículo do ensino médio, mas de relacionar o conhecimento da complexa e diversificada realidade dos jovens e integrar o trabalho dos professores em atividades pedagógicas coletivas e interessadas no aprofundamento da complexidade do conhecimento científico e cultural. Acima de tudo, valorizar os professores e implantar processos coletivos de formaçáo continuada. Pois é fundamental que os atores escolares sejam desafiados a articularem diferentes dimensóes da ação educativa.

Um dos desafios é que a escola comporte uma dinâmica de aprendizagem em sintonia com a sociedade contemporânea. O debate sobre o significado desse desafio e sobre suas consequências para a formação cidadá é parte da agenda da comunidade escolar. Pois o ensino médio se constituiu em um campo de disputas políticas, e uma reforma pode atender a objetivos antagônicos, que tanto podem ter compromisso com uma formação crítica e reflexiva quanto reforçar uma formação aligeirada e/ou reducionista. As políticas educacionais do século $\mathrm{XX}$ foram férteis nessa segunda perspectiva.

A ideia recorrente no período das contrarreformas educativas da década de 1990 foi a intrínseca relação entre educação enquanto uma dimensão fundamental para melhorar a distribuição de renda e como requisito para empregabilidade. Mesmo com a promulgação da Lei de Diretrizes e Bases da Educação Nacional (LDB) de 1996, que reconheceu o ensino médio na condição de uma etapa da educação básica, a terceira e última, com a responsabilidade de: consolidar e aprofundar os conhecimentos adquiridos no ensino fundamental para prosseguimento dos estudos; de dar uma preparaçáo básica para o trabalho e para a cidadania, com desenvolvimento da autonomia intelectual e do pensamento crítico, aliando teoria e prática. 
Ou seja, o texto da LDB enunciou a articulação entre a formação do ensino médio e a formação para o trabalho, o que tornaria possível uma organização a partir desse modelo se não fosse o Decreto $\mathrm{n}^{\circ} 2.208 / 97$, editado pelo então presidente Cardoso (1995-2002), que proibiu a junção da oferta. Com esse decreto, o ensino médio assumiu um caráter propedêutico. Esse fato aprofundou a crise de identidade do ensino médio, mas sobretudo forçou os alunos das classes populares, geralmente trabalhadores, a ficarem mais tempo em escolas estruturalmente precárias, tanto física quanto pedagogicamente.

Com isso, a partir de 1997, houve uma significativa expansão do ensino profissional privado no país, pois eram poucas as vagas públicas ofertadas em um cenário de altas demandas de qualificação profissional e altos índices de desemprego. Essa síntese da trajetória do ensino médio no século XX leva a crer que a Lei $\mathrm{n}^{\circ}$ 13.415/2017 guarda o mesmo espírito das políticas educacionais ocorridas no ensino médio brasileiro na ditadura varguista, na ditadura militar e nos anos 1990 .

Nos últimos 50 anos, tanto no Brasil como em outros países mais desenvolvidos, a visão sobre a educação assumiu um contorno mais mercantilista, uma presença forte na perspectiva de produção de recursos (conhecimentos e competências) com eficácia e eficiência. Recursos esses tanto úteis para os indivíduos em termos de inserção profissional quanto para toda a sociedade na competição global. Essa contradição foi vivenciada durante o período dos governos do Partido dos Trabalhadores (PT), que procurou uma difícil conciliação entre esses interesses com uma política de direito à educação. Mas ao contrário dos governos anteriores, foi priorizado o protagonismo dos movimentos sociais, sindicatos, associações acadêmicas e científicas.

\section{Políticas para o ensino médio e educação profissional (2003-2015)}

No Brasil, o cenário político do início do século XXI apontou para novas perspectivas orientadas para a construção dos direitos sociais básicos para a população mais pobre do país. A posse do presidente Luiz Inácio Lula da Silva (2003), figura histórica ligada aos movimentos sociais e um dos fundadores do PT, representou uma expectativa para um país historicamente marcado por desigualdades extremas e destituído de políticas sociais.

Quando teve início o governo Lula da Silva, as discussóes em torno da educação e do trabalho tomaram força no sentido de uma mudança de orientação das políticas educacionais até entâo mantidas com base na dicotomia formação, qualificação e certificação para o trabalho. Nesse período, o Ministério da Educação (MEC) organizou dois grandes seminários específicos do ensino médio e da educação profissional (maio/2003), que envolveram a comunidade acadêmica, 
sistemas escolares público e privado e os sindicatos que, reunidos, tiveram como pauta central a reconstituição da oferta, pelo sistema público de ensino, de uma educação integrada. A perspectiva era desenvolver uma política educacional com vistas ao aumento da escolarizaçáo dos jovens e adultos e a melhoria da qualidade da formação do trabalhador. Para tanto, havia um consenso da necessidade do governo fazer outra legislação que permitisse às escolas a oferta do ensino médio junto com a educação profissional (FERREIRA, 2011).

Foi assim que o Decreto no 5.154/2004 passou a organizar a educação profissional no país, sendo, posteriormente, transformado em lei (Lei no 11.741/2008). Essa lei alterou dispositivos da LDB, para redimensionar, institucionalizar e integrar as açóes da educação profissional técnica de nível médio, da educação de jovens e adultos e da educação profissional e tecnológica. A Lei no 11.741/2008 destaca que a preparação geral para o trabalho e, facultativamente, a habilitação profissional poderáo ser desenvolvidas nos próprios estabelecimentos de ensino médio ou em cooperação com instituições especializadas em educação profissional. A promulgação dessa lei pode ser considerada um avanço das políticas educacionais e uma resposta à luta de muitos professores pelo estabelecimento de uma política de Estado para a oferta integrada dos cursos técnicos com ênfase no processo de escolarizaçáo dos trabalhadores combinado com uma qualificação profissional (FERREIRA, 2016).

Houve também a reestruturação da educação profissional que continuou promovida por agentes públicos e privados e com modalidades diferenciadas de oferta, podendo permear ou não a educação escolar. A educação profissional técnica de nível médio é uma das três modalidades de educação profissional e tecnológica previstas pela legislação educacional brasileira (Lei n. 11.741/2008). Sua oferta pode ser "articulada" com o ensino médio ou "subsequente" para aqueles que já o tenham concluído. $\mathrm{Na}$ forma articulada, poderá ser "integrada" (habilitação profissional técnica de nível médio na mesma instituiçấo de ensino com matrícula única) ou "concomitante" (para quem ingresse ou já esteja cursando o nível médio, com matrícula distinta para cada curso). No caso da segunda alternativa, poderá ocorrer na mesma instituição ou em instituiçóes de ensino distintas aproveitando-se as oportunidades disponíveis, ou ainda em instituiçóes distintas mediante convênios de intercomplementaridade.

Dentre as iniciativas de âmbito nacional promovidas pelo MEC, na área de educação profissional e tecnológica, podemos destacar três: o Programa Nacional de Acesso ao Ensino Técnico e Emprego (Pronatec); o Programa Nacional de Integração da Educação Profissional com a Educação Básica na Modalidade de Educaçáo de Jovens e Adultos (Proeja); e o Programa Nacional de Inclusão de Jovens (Projovem Urbano e Projovem Campo).

Houve uma expansão da oferta da educação profissional nos últimos anos, motivada, sobretudo, por políticas e investimentos federais com foco no oferecimento de maiores oportunidades educacionais aos jovens em idade escolar adequada ao 
ensino médio. Isso foi feito por meio da educação profissional integrada ao ensino médio, como opção ao ensino médio regular e a ampliação da oferta dos cursos de qualificaçáo profissional para jovens e adultos em defasagem escolar, em articulação com a elevação da escolaridade. De tal maneira, procurou-se propiciar o resgate daqueles que não tiveram a oportunidade de completar sua escolarização aliada à formação profissional para o mundo do trabalho. Entre 2001 e 2013, o total de matrículas nessa modalidade de ensino cresceu 129,7\% (BRASIL, 2015).

O crescimento da oferta ocorreu tanto na rede pública (149\%) quanto na rede privada $(111,2 \%)$, tendo ambas mais do que duplicado as matrículas no período de 2001 a 2013. No contexto mais geral da expansão da educação profissional, é possível observar que o setor privado, antes com $51,2 \%$ da oferta passa a deter $47,0 \%$, cedendo espaço para a presença do setor público, que passa de $48,8 \%$ da oferta para 53,0\% em igual período. Parte considerável da expansão de matrículas ocorreu na rede federal de educação profissional e tecnológica (BRASIL, 2015).

Com a nova legislação, o governo implantou o Programa Ensino Médio Integrado e o Programa Nacional de Integração da Educação Profissional com a Educação Básica na Modalidade de Educação de Jovens e Adultos (Proeja). Ambos os programas têm por princípio pedagógico uma instrução politécnica. Essa proposta significa, acima de tudo, garantir o ensino médio como formação básica, necessária para todos os jovens e adultos, combinada com uma formação técnica. O conteúdo desses programas tem uma base filosófica e política densa porque compreende o horizonte da educação tecnológica para os trabalhadores, visando uma formação integral do ser humano e a superação da dualidade de classes (FRIGOTTO et al., 2005).

Tivemos também avanços na perspectiva do ensino médio como direito à educação básica a partir da Lei no 12.061, de 27 de outubro de 2009, que alterou a Lei no 9.394/96, para assegurar o acesso de todos os interessados ao ensino médio público. O que antes o Estado tinha como dever, assegurar uma progressiva extensão da obrigatoriedade e gratuidade ao ensino médio, com a nova lei, o Estado deve assegurar a universalizaçáo do ensino médio gratuito. Outro marco normativo é a Emenda Constitucional no 59, de 11 de novembro de 2009, que assegurou a educação básica obrigatória e gratuita dos 4 aos 17 anos de idade, inclusive sua oferta gratuita para todos os que a ela não tiveram acesso na idade própria que "remete não só à universalização, mas ao tratamento integrado do trajeto curricular a ser percorrido da educação infantil ao ensino médio" (KUENZER, 2011). Isso exige do poder público a promoção das condiçôes objetivas e, sobretudo, de uma articulação dos sistemas estaduais de educação. Pois, importante lembrar que os estados são os responsáveis pela oferta do ensino médio no país.

Do ponto de vista de uma nova configuração curricular, em 2012, uma nova legislação definiu as Diretrizes Curriculares Nacionais para o ensino médio (DCNEM). Essas diretrizes foram discutidas pelos segmentos das organizaçóes científicas e demais movimentos que militam pela educação secundária no Brasil. 
As diretrizes representam uma conquista de uma proposta curricular que reconhece a relação entre trabalho, ciência, tecnologia e cultura como eixo integrador dos conhecimentos na perspectiva do trabalho como princípio educativo.

Outro programa criado é o Ensino Médio Inovador, instituído pela Portaria no 971/2009, com o objetivo de apoiar e fortalecer os sistemas estaduais de educação na adoção de propostas curriculares inovadoras nas escolas de ensino médio não profissionalizantes. $O$ programa pretendeu superar a dicotomia ensino profissionalizante e ensino propedêutico a partir da diretriz de que o trabalho é um princípio educativo e deve mediar o processo pedagógico superando o limite do imediato e do utilitarismo do mercado. Portanto, a escola do ensino médio deve tratar do trabalho sem necessariamente ser profissionalizante. Para tanto, o programa criado pelo MEC propôs apoiar financeiramente e fortalecer a gestáo da escola, a formação dos professores e a participação e o protagonismo dos alunos por meio da instalação de fóruns.

No que tange à formação dos professores, em 2013, o MEC, em parceria com as Instituiçóes de Ensino Superior (IES) e as Secretarias Estaduais de Educação (SEDUs), instituiu o Programa Nacional de Formação de Professores e Pedagogos do Ensino Médio (PNEM), com propostas de instalar um processo de rediscussão das práticas docentes à luz das diretrizes curriculares para a formação da juventude do país. A formação teve como público-alvo os professores que atuam no ensino médio. Foi proposto um curso de formaçáo continuada composto por grupos de estudos, na escola, para aprofundamento e atualização de conceitos fundamentais que norteiam o ensino médio.

Importante chamar atenção para o Plano Nacional da Educação (20142024), um consenso no âmbito da sociedade brasileira. Grande parte do seu texto é resultado das conferências nacionais, estaduais e municipais de educação, nas quais os segmentos vinculados à educação no país puderam debater e apresentar diagnósticos e metas para a educação com vistas à consolidaçáo do Sistema Nacional de Educação. Dentre as metas, ressaltamos aquelas voltadas para a expansão e melhoria da qualidade do ensino médio e da educação profissional, todas com forte impacto no financiamento da educação. Por exemplo, com a meta 20, foi estabelecida a ampliação dos gastos públicos em educação para $10 \%$ do produto interno bruto (PIB).

Ao destacar essas recentes políticas para o ensino médio criadas nos governos do PT, o objetivo é lembrar o esforço coletivo realizado para enfrentar os difíceis problemas que assolam o ensino médio e a educação profissional. É sabido que erros foram cometidos nessa trajetória, que podem ser caracterizados, resumidamente, pela ausência de uma conduçâo mais orgânica de um projeto societário que fundasse um caminho mais seguro para a construçâo de uma educação assentada nos verdadeiros princípios republicanos. É preciso também fazer a crítica à postura antirrepublicana expressa nas variadas parcerias público-privadas conduzidas pelos governos do PT em todo esse período, as quais consolidaram a perspectiva da educação como mercadoria. 
$\mathrm{Na}$ esteira do que podemos sublinhar como erros cometidos pelos governos do PT, vale ainda ressaltar o seu empenho político quando fortemente investiu recursos financeiros e técnicos na ampliação do sistema de avaliação em larga escala na educação básica, constituído pelo Sistema de Avaliação da Educaçáo Básica (SAEB), a Prova Brasil e o Exame Nacional do Ensino Médio (ENEM.) Essa política de avaliação pode ser compreendida como uma resposta à lógica gerencialista voltada para resultados. A criação do Índice da Educação Brasileira (IDEB) segue essa mesma lógica, pois pode ser caracterizado como uma tecnologia que gera mais distorçóes do que benefícios para a compreensão da qualidade da educação brasileira. Os efeitos dessas avaliaçóes e índice, nesses dias atuais que contam com novos (e velhos) atores políticos, provocam maiores "estragos" e dão fôlego às contrarreformas.

O governo atual, que tomou de sobressalto o Estado brasileiro, radicaliza a comunhão com o setor privado interno e transnacional. Trata-se de uma radicalização neoliberal que ignora todos os esforços e a trajetória de direitos até aqui conquistados, trajetória essa construída com a participação de diversos segmentos da sociedade conforme relatado nesta sessão.

\section{A contrarreforma do ensino médio}

Em maio de 2016, o vice-presidente Michel Temer assumiu a presidência do país após o afastamento da presidente Dilma Roussef, por meio de um golpe parlamentar que ameaça o processo democrático no Brasil ${ }^{2}$. Imediatamente, Temer anunciou o slogan de seu governo: “ordem e progresso". Para "um dos interlocutores do presidente interino, a ideia é lembrar a necessidade de recuperar o país da desorganização política, econômica e social e retomar o crescimento econômico" (BERGAMO, 2016). Segundo o marqueteiro Elsinho Mouco, um dos responsáveis pela criação do novo conceito, a ideia é ter uma mensagem "forte, concisa e atual" (DECAT, 2016). Praticamente não houve comentários e nem resistências divulgadas pela grande mídia. Alguns jornalistas lembraram sobre a vinculação do lema à teoria positivista, mas os debates pararam aí, preferindo deixar à mostra um profundo desconhecimento histórico e, acima de tudo, ignorando os significados do uso de um lema do século XIX na segunda década do século XXI.

É certo que os símbolos revelam o imaginário construído e fazem parte da legitimação de qualquer contexto político. Quando Carvalho (1990) estudou as batalhas de símbolos e alegorias como parte integrante das batalhas ideológicas e políticas na construção da República brasileira, mostrou que a elaboração de um imaginário popular foi fundamental para a legitimação do novo regime político. Especificamente sobre a bandeira brasileira com sua divisa "ordem e progresso", de caráter difuso, projetava as aspiraçóes e os medos coletivos. Mas a incorporação dessa divisa (e o próprio desenho da bandeira) não se deram de forma rápida. 
Pelo contrário, foram alvo de disputas entre os grupos políticos da época. A vitória final ficou com os positivistas, que venceram as resistências sob argumentos de que tal "concepção era a base da nova dinâmica de confraternização universal, prenúncio da fase final de evolução da humanidade" (CARVALHO, 1990, p. 113).

No século XXI, o anúncio final da "evolução humana" está longe de acontecer e a confraternização humana mostra sinais decadentes. Sem dúvida, os mitos e símbolos continuam a frequentar o imaginário social como importante arma de legitimação dos jogos políticos e econômicos. Nesse caso, o slogan "ordem e progresso" pode agregar e se espalhar pelas cabeças de grande parte da população, que se encontra hoje no mundo das incertezas e riscos frequentes.

Nessa perspectiva da "ordem e progresso", o MEC apresentou uma contrarreforma do ensino médio assentada em argumentos sobre a importância da flexibilidade no percurso formativo do aluno e da necessidade de ampliar o tempo do aluno na escola como forma de provocar mais atratividade dessa etapa da educação básica. A avaliação do MEC é que, assim, o desempenho dos alunos vai melhorar já que é fraco quando comparado com outros países. Desse modo, a organização do ensino médio deverá ser dividida em áreas de conhecimentos diferentes e seguir uma base nacional comum.

Para compreender esses argumentos e o conteúdo da contrarreforma do ensino médio, é preciso observar as lógicas que perpassam diversos países do capitalismo ocidental e verificar que há um contexto comum de uma "agenda globalmente estruturada da educação" (DALE, 2004). Segundo Souza (2016), essa agenda consiste dominantemente em processos de padronização da educação, o que parece sinalizar uma redefinição do que se entende por educação. O que está em questão é a própria concepção de educação, simplificada na relação de estabelecimento de um currículo estandardizado focado em matemática e língua materna, com processos padronizados de testagem de resultados, garantidos por uma gestão focada nos resultados, que tensiona a redefiniçáo do trabalho docente, com o suporte de um padrão mínimo de financiamento educacional.

O currículo escolar, nessa perspectiva, não é uma escolha de cada comunidade local, mas um padrão global sobre o que é necessário (e legítimo) ensinar/aprender.

Para Dale (2004), o isomorfismo curricular observado, em nível mundial, não é produto da globalização, como se considera atualmente, mas possui uma história muito mais longa, associada à propagação dos valores e pressupostos da modernidade, tais como a racionalidade científica, o individualismo e o progresso. Variaçóes desses pressupostos têm dominado os debates sobre o currículo até bem pouco tempo, reconhecendo-se o lugar e o papel do currículo como o meio pelo qual os estados-naçóes alcançaram suas metas através da educação. Logo, podemos conferir a pertinência do slogan do governo Temer, cuja ordem autoritária impõe a contrarreforma do ensino médio por medida provisória. 
A questão fundamental aqui é, certamente, que a "educação" tem sido historicamente convocada a contribuir tanto para o pilar da regulaçáo quanto para o da emancipaçáo. Efetivamente, a ela têm sido atribuídos dois papéis diferentes e contraditórios na manutenção da relação entre o Estado e a sociedade e, realmente, muitas das batalhas sobre o conteúdo do currículo náo apenas têm refletido, mas foram, precisamente, marcadas por essa tensão (DALE, 2008, p. 16).

Lessard e Carpentier (2016) destacam que as críticas frequentes à educação abalaram a confiança no progresso das sociedades por meio dela e isso acarretou mudanças importantes. Uma das medidas adotadas foi o estreitamento dos currículos, o prolongamento dos dias e anos letivos e a padronização do desempenho escolar. O estreitamento do currículo foi acompanhado de uma centralização de um currículo nacional.

Esses fatos reforçam a compreensão de como a contrarreforma do ensino médio é parte integrante de uma agenda globalmente estruturada da educação. Os exemplos utilizados pelos defensores dessas mudanças são frágeis, mas confirmam os padróes de governança internacional, cuja missão modernizadora é reduzir a educação (e o conhecimento) a funções mínimas de acordo com as necessidades imediatas da sociedade capitalista contemporânea. Tarefa essa que deverá ser cumprida crescentemente pelos mercados educacionais.

Um exemplo de sucesso utilizado pelos defensores da contrarreforma é a política implantada em Pernambuco. Algumas pesquisas (BENITTES, 2012; NOBREGA, 2014; CAVALCANTI \& VELOSO, 2014) sobre o Programa de Modernização da Gestão Pública-Metas para Educação (PMGP-ME) e o Programa de Educação Integral (PEI) ali implantados ressaltam que a Política de Ensino Médio em Pernambuco, ao articular os objetivos de modernização da gestão pública com os objetivos da educação integral, inverte a prioridade dos fins pelos meios, produzindo um deslocamento das finalidades educacionais da formação humana em suas múltiplas dimensóes para a mensuração excessiva centrada em modelos administrativos das organizações privadas. Ademais, essa política não é implantada em toda a rede estadual, favorecendo mais desigualdades entre alunos e professores que passam por processos seletivos para terem o direito a essa escola "moderna".

Um segundo exemplo geralmente citado é o sistema educacional da Finlândia, referenciado por muitos como exemplo de qualidade. É importante lembrar que esse sistema é completamente público, da educação básica ao ensino superior. O governo finlandês não permite, por exemplo, que haja alguma escola privada porque acredita que os cinco milhóes de jovens finlandeses devem estudar na mesma escola, isto é, naquela mantida pelo poder público, com verba pública e voltada para os interesses da sociedade (SENKEVICS, 2013).

Além do investimento alto na formação e na capacitação docente, há um importante diferencial: lá, os professores são bem remunerados. De fato, a profissão docente é disputada entre jovens. A Finlândia é o antídoto a esse movi- 
mento que impóe provas padronizadas, privatizaçáo de escolas públicas e remunera os professores com base em avaliaçôes de desempenho que se tornou típico de diversos sistemas educacionais pelo mundo (SENKEVICS, 2013).

Outro exemplo referenciado são os sistemas educacionais de países desenvolvidos da Organizaçáo para a Cooperação e Desenvolvimento Econômico (OCDE). Em pesquisa realizada por Baudelot e Establet, em 2009, sobre a escola francesa no contexto do Programa Internacional de Avaliação de Alunos (PISA), os sociólogos trazem dados reveladores que desbancam os argumentos dos reformistas neoliberais. Eles afirmam que a escola francesa é uma das melhores do mundo para pouco menos da metade de seus alunos e uma das piores para a outra metade.

Entre tantas questóes colocadas pelos autores, duas se relacionam mais diretamente com o que estamos vivendo com a contrarreforma do ensino médio que flexibiliza o currículo por meio de trajetórias individuais e estratificadas. Baudelot e Establet (2009) lançam perguntas sobre a organização da educação de países desenvolvidos: uma seleção precoce, visando a isolar, desde os dez anos de idade, uma populaçáo destinada a formar a elite da nação como a escola alemá, favorece a elevação do nível geral? Os países que retardam o momento onde os alunos devem escolher sua orientaçáo possuem os melhores resultados do que aqueles que os sistemas educativos são mais estratificados? De acordo com análises feitas a partir do PISA, eles respondem que todos os sistemas que praticam abertamente as seleçôes precoces são mais desiguais e menos eficazes.

Os cinco países da OCDE (Austrália, Canadá, Finlândia, Japão e Coreia do Sul) que, em 2006, tiveram uma perfomance melhor do que a média em ciências superiores e têm um impacto do meio social sobre a performance do alunos inferior a média não praticam a diferenciação precoce dos alunos (BAUDELOT \& ESTRABLET, 2009). Ou seja, não têm uma organização de ensino "flexibilizada" tal como colocada pela Lei no $13.415 / 2017$.

Outras pesquisas citadas por Duru-Bellat (2009) mostram que as desigualdades sociais entre alunos são mais moderadas quanto o "tronco comum" é longo. $\mathrm{O}$ inverso acontece em países que têm orientação precoce. Por sua vez, os países da OCDE cujos sistemas de educação são mais estratificados têm a tendência de ter os resultados mais baixos no PISA.

\section{Considerações finais}

Este artigo destacou as recentes políticas para o ensino médio no Brasil, desenvolvidas nos governos do PT, com o objetivo de situar a ação pública democrática desenvolvida na constituição de políticas voltadas para enfrentar os difíceis problemas dessa etapa da educação básica. Tais políticas, protagonizadas pelo Ministério da Educação, procuraram induzir adoção de programas pelos estados por 
meio de apoio técnico e financeiro. Contudo, a pluralidade de programas em execução de diferentes matrizes ideológicas e a ausência de mecanismos financeiros mais consistentes, dificultaram a organizaçáo de um projeto para o ensino médio. De forma geral, os erros cometidos nessa trajetória podem ser caracterizados pela ausência de conduçáo mais orgânica de um projeto societário que fundasse um caminho mais seguro para a construção de uma educação assentada nos verdadeiros princípios republicanos.

As portas para o retrocesso ficaram abertas no contexto de uma globalizaçáo cada vez mais neoliberal. A experiência histórica aponta que essa contrarreforma não alcançará uma melhoria da qualidade do Ensino Médio. Muito pelo contrário, ela tende a piorar o desempenho dos nossos alunos e aumentar a desigualdade escolar.

Pois, de fato, para alterar a qualidade do que é oferecido no Ensino Médio e ampliar as possibilidades de acesso, a permanência e sua conclusão, seria necessário um conjunto articulado de açôes envolvendo, para sua execução, as redes de ensino e esferas de poder em torno de uma ação conjunta e de um projeto societário republicano com vistas à emancipação política e cultural das nossas juventudes. Projeto esse que está na voz de muitos jovens em diversos espaços educativos.

\section{Notas}

1. Exame necessário para os estudantes secundaristas franceses darem entrada no Ensino Superior.

2. De acordo com Proner (2016), professora de Direito Internacional da Universidade Federal do Rio de Janeiro, assim como em alguns países da América Latina que vivem outros tipos de golpismos no século XXI, há o reconhecimento de que o Brasil passa por um golpe parlamentar, compreendido como abreviaçấo do mandato presidencial por um Congresso Nacional eivado de ilegitimidade com mais de $60 \%$ de seus membros envolvidos em processos de corrupção. Boaventura de Souza Santos (2016) segue nessa mesma interpretação ao explicar o afastamento da Presidente Dilma Roussef como uma ameaça à democracia.

\section{Referências}

BAUDELOT, C.; ESTABLET, R. L'élitisme républicain: l' école française à l' épreuve des comparaisons internationales. Paris: Seuil, 2009.

BEHRING, E.R. Brasil em contra-reforma: desestruturação do Estado e perda de direitos. São Paulo: Cortez, 2003.

BENITTES, V.L.A. A política de ensino médio no estado de Pernambuco: um protótipo de gestão da educação em tempo integral". 2012. Disponível em: $\leq$ http://repositorio.ufpe.br/ handle/123456789/11301>. Acesso em: 21 nov. 2016.

BERGAMO, M. Slogan do governo Temer será 'Ordem e progresso'. Folha de S.Paulo, 12 maio 2016. Disponível em: <http://www1.folha.uol.com.br/colunas/ 
monicabergamo/2016/05/1770509-slogan-do-governo-temer-sera-ordem-e-progresso.

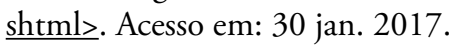

BRASIL. Ministério da Educação. Expansão da educação profissional. Brasil: Ministério da Educação, 2015.

CARVALHO, J.M. A formação das almas. São Paulo: Companhia das Letras, 1990.

CAVALCANTI, C.; VELOSO, C. Gestão escolar e avaliação educacional: impactos do programa de modernização da gestão pública/metas para educação do estado de Pernambuco. 2014. Disponível em: shttp://www.fundaj.gov.br/images/stories/epepe/V EPEPE/EIXO_8/CarolinedaSilvaCavalcanti-CO08.pdf>. Acesso em: 21 nov. 2016.

CONFERÊNCIANACIONALDEEDUCAÇÃO(CONAE).Documentofinal.Brasília,2014. Disponível em: <http://conae.mec.gov.br/images/stories/pdf/pdf/documetos/documento_ final sl.pdf $>$. Acesso em: 02 fev. 2017.

CUNHA, L.A. Educação, Estado e democracia no Brasil. São Paulo: Cortez, 1991.

DALE, R. A globalização e o desenho do terreno curricular. Espaço do currículo, v. 1, n. 1, p. 12-33, mar./set. 2008.

. Globalização e educação: demonstrando a existência de uma "cultura educacional mundial comum" ou localizando uma "agenda globalmente estruturada para a educação"? Educação e Sociedade, Campinas, v. 25, n. 87, p. 423-460, maio/ago. 2004. Disponível em: shttp://www.cedes.unicamp.br>. Acesso em: 20 jul. 2015.

DECAT, E. “Governo Federal: Ordem e Progresso” será o slogan de Temer. Estadão, 12 maio 2016. Disponível em: <http://politica.estadao.com.br/noticias/geral,governofederal-ordem-e-progresso-sera-o-slogan-do-governo-temer,10000050764>. Acesso em: 28 jan. 2017.

DURU-BELLAT, M. Universelles, les inégalités sociales face à l'école ? In: DURUBELLAT, M.; VAN ZANTEN, A. Sociologie du système éducatif: les inégalités scolaires. Paris: PUF, 2009.

ENGUITA, M.F. A encruzilhada da instituição escolar (prefácio). In: KRAWCZYK, N. (Org.). Sociologia do ensino médio: crítica ao economicismo na política educacional. São Paulo: Cortez, 2014.

FERREIRA, E.B. Ensino médio no Brasil: os desafios das políticas de garantia do direito a sua universalização. Linhas Críticas, Brasília, v. 17, n. 34, 2011.

. Secondary under tension between democratization and modernization: reflections from the Brazilian experience. International Education Studies, v. 9, n. 9, p. 157-169, 2016. FRIGOTTO, G. A produtividade da escola improdutiva. São Paulo: Cortez, 1988.

FRIGOTTO, G.; CIAVATTA, M.; RAMOS, M. (Orgs.). Ensino médio integrado: concepção e contradiçôes. São Paulo: Cortez, 2005.

KRAWCZYK, N. O ensino médio no Brasil. São Paulo: Ação Educativa, 2009.

KUENZER, A. A formação de professores para o Ensino Médio: velhos problemas, novos desafios. Educação e Sociedade, v. 32, n. 112, p. 667-688, set. 2011. 
LESSARD, C.; CARPENTIER, A. Políticas educativas: a aplicação na prática. Rio de Janeiro: Vozes, 2016.

MERLE, P. La démocratisation de l'enseignement entre égalisation et illusions. In: DURU-BELLAT, M.; VAN ZANTEN, A. Sociologie du système éducatif: les inégalités scolaires. Paris: PUF, 2009.

NOBREGA, S.A. Programa de modernização do estado de Pernambuco: impactos no trabalho docente. 2014. Disponível em: <http://www.editorarealize.com.br/revistas/conedu/traba lhos/Modalidade 4 datahora $15 \quad 08 \quad 2014 \quad 23 \quad 38 \quad 13$ idinscrito $33355 \quad 1$ dab 67cf1e7718fd05d4b23ba8776dc9.pdf>. Acesso em: 28 nov. 2016.

NORA, P. O retorno do fato. In: LE GOFF, J.; NORA, P. História: novos problemas. Rio de Janeiro: Francisco Alves, 1988.

PRONER, C. Golpe branco no Brasil: Dilma alerta na ONU. In: PRONER, C. et al. A resistência ao golpe de 2016. Bauru: Canal 6, 2016.

SANTOS, B.S. Os perigos da desordem jurídica no Brasil. In: Golpe branco no Brasil: Dilma alerta na ONU. In: PRONER, C. et al. A resistência ao golpe de 2016. Bauru: Canal 6, 2016.

SENKEVICS, A. Educação na Finlândia: o que tem de tão especial? Ensaios de gênero, 24 fev. 2013. Disponível em: <https://ensaiosdegenero.wordpress.com/2013/02/24/ educacao-na-finlandia-o-que-tem-de-tao-especial/>. Acesso em: 13 nov. 2016.

SOUZA, A.R. A teoria da agenda globalmente estruturada para a educação e sua apropriação pela pesquisa em políticas educacionais. RBPAE, v. 32, n. 2, p. 463-485, maio/ago. 2016. Disponível em: <http://www.seer.ufrgs.br/rbpae/article/viewFile/63947/38376>. Acesso em: 15 dez. 2016.

Recebido em 04 de março de 2017.

Aprovado em 10 de abril de 2017. 